\title{
Subjective wellbeing among rheumatic heart disease patients at Tikur Anbessa Specialized Hospital, Addis Ababa, Ethiopia: observational cross-sectional study
}

\author{
Henok Tadele ${ }^{1 *}$, Hayat Ahmed ${ }^{1}$, Helen Mintesnot ${ }^{1}$, Etsegenet Gedlu' ${ }^{1}$, Senbeta Guteta ${ }^{2}$ and Dejuma Yadeta ${ }^{2}$
}

\begin{abstract}
Background: Subjective wellbeing (SWB) is a self-reported positive life judgment and good feeling. RHD, rheumatic heart disease, is a long-term sequel of single or recurrent acute rheumatic fever. There are no studies that assessed SWB in RHD patients. We aimed to assess SWB among RHD subjects enrolled in chronic care at Tikur Anbessa Specialized Hospital (TASH), Ethiopia.

Methods: This observational cross-sectional study employed a validated Amharic WHO-5 wellbeing index to assess SWB. Sociodemographic and clinical data were collected using structured questionnaire. RHD subjects aged 9 years and above were included. Factors associated with SWB were assessed using logistic regression models.

Results: The study included 384 subjects, females 68.2\% (262). Children, < 18years, constituted one third of study subjects, $32.8 \%$ (126). Moderate and severe echocardiographic RHD dominated, $85.9 \%$ (330) with no associated comorbidity, $84.4 \%$ (324). Only 17.2\% (66) had surgical or device intervention. Poor SWB was documented in 9.6\% of study subjects (95\% Cl: 6.88-13.04). On multivariable regression, those with younger age RHD diagnosis, <20years, had almost three times higher odds of poor SWB, adjusted odds ratio (aOR) 2.69(95\% Cl: 1.30-5.58, P 0.008). Those with monthly family income of < 1000 Ethiopian Birr had three times higher odds of poor SWB, aOR 2.97(95\% Cl: 1.24-7.1, P 0.014). Study subjects who had good medication adherence had reduced odds of poor SWB, aOR 0.37(95\% Cl: $0.18-0.77, P$ 0.028). Those who received psychologic support from their families also had reduced odds of poor SWB, aOR 0.26(95\% Cl: 0.11-0.64, P 0.003).

Conclusion: Poor SWB was documented in one-tenth of RHD patients. Family income, younger age at RHD diagnosis, medication adherence and psychological support predicted poor SWB. Poor SWB has to be considered and assessed among RHD patients particularly among those with younger age at RHD diagnosis and poor family income. Further mixed studies are recommended to assess how medication adherence and psychological supports associate with positive SWB among RHD patients.
\end{abstract}

Keywords: Subjective wellbeing, Rheumatic heart disease, Depression, Ethiopia

*Correspondence: henny_2007@yahoo.com

${ }^{1}$ Department of Pediatrics and Child Health, Cardiology Division, School of Medicine, College of Health Sciences, Addis Ababa University, Addis Ababa, Ethiopia

Full list of author information is available at the end of the article

\section{Background}

Health is defined by the World Health Organization (WHO) as a state of complete physical, mental and social wellbeing, and not merely an absence of disease [1]. Good health and wellbeing are included as the third 
Sustainable Development Goal (SDG) by the United Nations [2]. Wellbeing is defined as a self-reported positive life judgement and good feeling [3]. Subjective wellbeing (SWB) assesses affective and cognitive evaluation of a person's life [4]. SWB is measured using selfreport of affective and cognitive domains by different measures $[3,5]$. While several measures were extensively studied in developed nations, a validated SWB assessment tool was not made available till 1998 when WHO introduced a new SWB measure for wider use at global scale. The WHO-5 wellbeing index uses a questionnaire that assesses the current mental wellbeing (in the last 2 weeks) of a subject. It contains 5 simple questions which were produced after several revisions during clinical trials. It was revised only to have positively phrased questions to increase study subject acceptance and to avoid negative symptom related issues [6]. A systematic review of the literatures was conducted to assess the validity of the WHO-5 wellbeing index for depression screening and outcome measures in several clinical trials, and it was reported as a valid screening tool [7].

Rheumatic heart disease (RHD) is the long-term cardiac sequelae caused by a single severe or recurrent acute rheumatic fever episodes [8]. RHD is believed to be the disease of the poor owing to its high prevalence in these low income settings in the face of effective preventive strategies [9]. Echocardiography based Ethiopian studies documented RHD to be a very common (highly endemic) among school children [10], and RHD was also reported as the top cardiac disease among cardiac patients receiving chronic care in the main referral centers [11]. A national guideline for treatment, prevention and control as well as RHD registries was published by the Ethiopian Ministry of Health [12]. Seven action points for RHD eradication in Africa were forwarded using the Addis Ababa communiqué. These action points include establishment of RHD registries, ensuring benzathine penicillin availability, access to universal reproductive health services for women with RHD, decentralizing the RHD services to districts, increasing cardiac surgery centres, multisectoral collaboration, and cultivating partnership to ensure the application of the action points [13]. The African Union also took an initiative to embark on RHD eradication from Africa [14].

Studies have documented that RHD patients suffer from a great deal of depression and anxiety [15]. An international study on a review of the world mental health surveys concluded mental disorders particularly anxiety-mood disorders as common problems among heart disease patients [16]. High level of cardiac disease anxiety was postulated to be the predisposing factor for depression $[15,16]$.
Positive wellbeing is considered to be protective for cardiovascular diseases/events and grants long life. Proposed mechanisms are interrelated including adaptive physiologic functioning, promotion of positive health behaviors, and buffering the effect of stress on health. Moreover, good health would also bring positive wellbeing [17-19]. Wellbeing index has been shown to increase after cardiac rehabilitation among ischemic heart disease and obese patients [20]. Compared to other screening tools, the WHO- 5 wellbeing index has been shown to be a reliable SWB screening tool among patients with chronic illnesses [21]. Definitive surgical or percutaneous treatments for RHD are not readily available in Ethiopia and hence patients live with severe manifestations and complications of RHD affecting their quality of life [22]. There are no studies that assessed the SWB in RHD patients. Hence, we aimed to assess SWB and its determinants among RHD patients enrolled on chronic care at the only tertiary national cardiac referral center for Ethiopia.

\section{Methods \\ Study area}

The study was conducted in Addis Ababa, Ethiopia at Tikur Anbessa Specialized Hospital (TASH). It is the teaching hospital of Addis Ababa University, College of Health Sciences, and School of Medicine. It is also the largest referral hospital in Ethiopia with multiple specialties and sub-specialties. It is the national referral cardiac center. There are over 5000 RHD patients aged 9 years and above enrolled in chronic care and follow up. Pediatrics and adult cardiac clinics are attended by consultant pediatric / adult cardiologists, pediatric/ adult cardiology fellows, pediatric/ internal medicine residents and trained nurses.

\section{Study design and study period}

The study employed cross-sectional study design and it was conducted between December 2020 and May 2021.

\section{Study population}

The study population was all children above the age of 9 years and adults with RHD attending follow up at the pediatric and adult cardiology clinics.

\section{Sample size and sampling procedure}

A sample size of 384 was calculated using assumptions of $50 \%$ poor SWB among RHD patients, 95\% confidence level with $5 \%$ margin of error and a power of 80 . A proportion of $50 \%$ poor SWB was used as there are no previous studies on SWB among RHD patients. There was an existing RHD registry in both adult and Pediatric Cardiology clinics and it was used as sampling frame. Subjects 
aged 9 years and above were included, and simple random sampling technique (manual lottery method) was used to identify or select study subjects by the data collectors as they show up for follow up. The pediatric to adult cardiac patients' sample selection was made using proportional to sample size allocation.

\section{Inclusion and exclusion criteria}

All RHD patients aged 9 years and above with established echocardiographic diagnosis and who were on follow up for over 6 months were included in the study. Study subjects with acute illness like heart failure and subjects with previously diagnosed or acute psychiatric illness were excluded from the study as they required immediate medical attention and care.

\section{Data collection}

Demographic and clinical data were collected using structured questionnaire prepared for the purpose of this study and pretested on non-participating patients. Subjective Well-being (SWB) was assessed using a validated Amharic translated WHO- 5 wellbeing tool [23]. The tool is approved for use among children above 9 years of age, adolescents as well as adults. It has 5 statements on how patients have been feeling over a period of 2 weeks before the time of the study. A scale of $0-5$ is provided in descending order to rate the amount of time the feelings lasted. Higher numbers indicate better subjective well-being. The raw score is calculated by totaling the figures of the five answers. The raw score ranges from 0 to 25,0 representing worst possible and 25 representing best possible quality of life. A raw score below 13 indicates poor wellbeing and is an indication for assessment of depression. Clinical and sociodemographic data were collected by BSc Nurses who received a one-day training on the tools. The quality of collected data was checked daily by investigators.

\section{Variables}

The dependent variable was subjective well-being score. Independent variables include age, gender, address, distance from the health facility/TASH, education, marital status, number of children, family income, occupation, age at RHD diagnosis, New York Heart Association (NYHA) functional class, severity of RHD, any comorbidity, comorbid chronic illness, RHD related complication, number of drugs, medication adherence, history of cardiac intervention, psychological support, hospital admission in the last 1 year, and nutritional status.

\section{Operational definitions}

Rheumatic heart disease was defined as damage to the heart, particularly the heart valves, after having one or more attacks of rheumatic fever [8]. NYHA functional status was functional classification of patients according to cardiac functional capacity [24]. Subjective well-being was defined as a self-reported positive life judgment and good feeling [3]. WHO subjective well-being index is a questionnaire that assesses the current mental wellbeing in the last 2 weeks of a subject using five questions [6]. Rheumatic heart disease was classified as mild, moderate and severe based on the World Heart Federation Criteria as assessed by echocardiography [25]. Medication adherence was assessed based on patient self-report. Good adherence was considered when patient had taken $\geq 80 \%$ of prescribed medications before clinic visit date while satisfactory adherence was considered when between 60 and $80 \%$ of medications were taken. Poor adherence was considered when $<60 \%$ of prescribed medications were taken. Psychological support was defined as any form of support provided to the patient in terms of reminder of follow up visits, pill time reminders, accompany during ill periods or clinic visits, and provision of hope and encouragement.

\section{Data analysis}

Data completeness was checked manually and entered into Statistical Software for Social Sciences (SPSS) version 25 for analysis. Chi-square analysis was conducted to check for univariate association. Then, variables with $p$ value less than 0.05 were selected from binary regression for final multivariable logistic regression analysis. Association between dependent and independent variables was measured using odds ratio and 95\% confidence intervals. $P$ value less than 0.05 was set as statistically significant.

\section{Results}

\section{Sociodemographic characteristics and SWB scores of study subjects}

A total of 402 study subjects were approached, and 18 were excluded (8 cases of heart failure requiring admitted care, 2 cases of acute or previous psychiatric illness, and 8 cases of non-consent). And, finally this study included 384 study subjects with female predominance, $68.2 \%$ (262). The mean age of study subjects was $27.03 \pm 12.85$ years. Children below the age of 18 years constituted $32.8 \%$ (126) of study subjects. Majority of study subjects were from Addis Ababa, 49.7\% (191) followed by Oromia region, 32.3\% (124). Majority of study subjects lived within $100-\mathrm{km}$ from the study health facility (TASH) or Addis Ababa, 56.5\% (217). Majority of them also had completed primary education and above, $86.6 \%$ (333).

Concerning marital status, majority of study subjects were single, $57.3 \%$ (220). One hundred fifty-six (40.6\%) of study subjects were students. Almost $80 \%$ of study 
subjects had a monthly family income of 1000 and above Ethiopian birr. There was no difference in SWB between children and adults. No association was noted with sex, residence and distance from health facility, occupation, and SWB. Only family income was associated with SWB from sociodemographic variables (See Table 1).

Table 1 Sociodemographic characteristics and Chi-square analysis outputs of Rheumatic Heart Disease study subjects at Tikur Anbessa Specialized Hospital, 2021

\begin{tabular}{|c|c|c|c|c|c|}
\hline \multirow[t]{2}{*}{ Variable } & \multirow[t]{2}{*}{ Frequency(n) } & \multirow[t]{2}{*}{ Percentage (\%) } & \multicolumn{3}{|c|}{ SWB: $\mathrm{n}(\%), P$ value } \\
\hline & & & Poor & Normal & $P$ value \\
\hline Age (yrs) & & & & & 0.248 \\
\hline$<18$ & 126 & 32.8 & $9(7.1)$ & 117(92.9) & \\
\hline$\geq 18$ & 258 & 67.2 & $28(10.3)$ & 230(89.1) & \\
\hline Sex & & & & & 0.516 \\
\hline Male & 122 & 31.8 & $10(8.2)$ & 112(91.8) & \\
\hline Female & 262 & 68.2 & $27(10.3)$ & 235(89.7) & \\
\hline Address: Regions & & & & & 0.631 \\
\hline Addis Ababa & 191 & 49.7 & $22(11.5)$ & 169(88.5) & \\
\hline Oromia & 124 & 32.3 & $11(8.9)$ & 113(91.1) & \\
\hline Amhara & 36 & 9.4 & $3(8.3)$ & 33(91.7) & \\
\hline SNNPR & 32 & 8.3 & $1(3.1)$ & $31(96.9)$ & \\
\hline Others & 1 & 0.3 & $0(0)$ & $1(100)$ & \\
\hline Distance from follow up health facility (in kilometers) & & & & & 0.281 \\
\hline$<100$ & 217 & 56.5 & $26(12)$ & $191(88)$ & \\
\hline 100-199 & 47 & 12.2 & $3(6.4)$ & 44(93.6) & \\
\hline $200-299$ & 55 & 14.3 & $5(9.1)$ & $50(90.9)$ & \\
\hline$\geq 300$ & 65 & 16.9 & $3(4.6)$ & $62(95.4)$ & \\
\hline Educational Status & & & & & 0.159 \\
\hline Illiterate & 40 & 10.4 & $7(17.5)$ & $33(82.5)$ & \\
\hline Can read and write & 11 & 2.9 & $1(9.1)$ & 10(90.9) & \\
\hline Primary education (1-8) & 148 & 38.5 & $8(5.4)$ & 140(94.6) & \\
\hline Secondary education (9-12) & 118 & 30.7 & 14(11.9) & 104(88.1) & \\
\hline College level (Certificate/diploma/first degree/MS/MD/PHD) & 67 & 17.4 & $7(10.4)$ & $60(89.6)$ & \\
\hline Marital status & & & & & 0.426 \\
\hline Married & 153 & 39.8 & 17(11.1) & 136(88.9) & \\
\hline Single, divorced, separated or widow & 231 & 60.2 & 20(8.7) & 211(91.3) & \\
\hline Number of your children & & & & & 0.216 \\
\hline One & 42 & 10.9 & $5(11.9)$ & $37(88.1)$ & \\
\hline Two & 59 & 15.4 & 10(16.9) & 49(83.1) & \\
\hline Three & 21 & 5.5 & $2(9.5)$ & 19(90.5) & \\
\hline Four and above & 30 & 7.8 & $1(3.3)$ & $29(96.7)$ & \\
\hline Occupation & & & & & 0.441 \\
\hline Student & 156 & 40.6 & $11(7.1)$ & 145(92.9) & \\
\hline Government employee & 40 & 10.4 & $3(7.5)$ & $37(92.5)$ & \\
\hline Self-employed & 71 & 18.5 & 10(14.1) & $61(85.9)$ & \\
\hline Housewife & 92 & 24 & $9(9.8)$ & $83(90.2)$ & \\
\hline Others (Farmer, daily laborer) & 25 & 6.5 & $4(16)$ & $21(84)$ & \\
\hline Family monthly income (Ethiopian Birr) & & & & & 0.008 \\
\hline$<1000$ & 80 & 20.8 & 15(18.8) & $65(81.3)$ & \\
\hline 1000-2999 & 155 & 40.4 & $11(7.1)$ & 144(92.9) & \\
\hline$\geq 3000$ & 149 & 38.8 & $11(7.4)$ & 138(92.6) & \\
\hline
\end{tabular}




\section{Clinical characteristics and SWB scores of study subjects}

The mean age at RHD diagnosis was $17.14 \pm 10.78$ years. Majority of our study subjects had moderate to severe RHD as assessed by echocardiography, 85.9\% (330). Most of our study subjects didn't report any associated comorbidity, $84.4 \%$ (324). Seizure disorders, hypertension and HIV were the common reported comorbidities.

Most of our study subjects were in NYHA class I and II during the time of assessment, $62.5 \%$ (240). Heart failure, $12.5 \%$ (48), was the common reported RHD complication. Stroke and rheumatic recurrence occurred in $4.9 \%$ (19) and $4.7 \%$ (18) of study subjects, respectively. Almost all of our study subjects were on multiple medications for RHD, 97.7\% (375) and majority reported good medication adherence, $77.4 \%$ (297).

Most of study subjects received psychologic support from their families, $90.9 \%$ (349). A quarter of them had hospital admission in the last 1 year, 26\% (100). A little over one- tenth of study subjects had surgical intervention for their RHD, 17.2\% (66). Majority of study subjects had normal anthropometric indices, 87.8\% (337). Age at RHD diagnosis, medication adherence and psychological support showed association with SWB. However, RHD severity, NYHA class, comorbidities, RHD related complications, number of medications taken, RHD intervention, hospital admission in the last 1 year, and nutritional status didn't show any association with SWB (See Table 2).

\section{Subjective wellbeing score}

Poor SWB was reported in 9.6\% (95\% CI: 6.88-13.04) of study subjects. Worst SWB of 0 or feeling at no time was commonly reported for a question that asks 'daily life is filled with things that interest me', 5.2\% (20). Response of sometimes was commonly reported for a question that asks 'I have felt active and vigorous', 5.7\% (22). The best SWB response of all of the time was documented for the question that asks 'I woke up feeling fresh and rested', 50.8\% (95) (See Table 3).

\section{Factors associated with SWB among RHD study subjects}

Study subjects with family income of $<1000$ ETB per month had three times higher odds of poor SWB, aOR 2.97(95\%: 1.24-7.1, P 0.014). Those with younger age RHD diagnosis, $<20$ years, had almost three times higher odds of poor SWB, aOR 2.69(95\% CI: 1.30-5.58, P 0.008). Study subjects who had good medication adherence had reduced odds of poor SWB, aOR 0.37(95\% CI: 0.18-0.77, $P$ 0.028). Those who received psychologic support from their families also had reduced odds of poor SWB, aOR 0.26(95\% CI: 0.11-0.64, P 0.003) (See Table 4).

\section{Discussion}

Our Study is the first to report SWB and its determinants among RHD patients from a large study sample. Unmarried females with RHD diagnosis at second decade of life predominated the study population. Children constituted one third of study subjects. Majority had moderate to severe RHD disease severity on echocardiography with no associated comorbidity. Most of our study subjects had mild to moderate clinical symptoms during the study and lived within 100-km from the follow up health facility. Heart failure was the most common reported RHD complication. Majority were on multiple medications with good adherence. Families provided psychologic support in most cases. A quarter had hospital admission in the last 1 year. Only a little over one tenth of them had surgical intervention for RHD. Poor SWB was reported in one tenth of RHD patients. Family income, age at RHD diagnosis, medication adherence and psychological support predicted poor SWB among RHD subjects.

Majority of our study subjects were females. Previous echocardiography based Ethiopian RHD studies documented consistently female predominance $[10,11,26]$. Higher autoimmunity with effect of sex hormones and better RHD detection during antenatal care in the reproductive age women were postulated reasons for higher RHD occurrence in females. More severe valvular lesions were also documented among females [27]. Social factor like child raising which increases ARF/RHD susceptibility are also incriminated as plausible explanation [28]. In our study, most of RHD subjects were not married. Ugandan study had documented presence of stigma and discrimination among patients with RHD [29]. Presence of cardiac symptoms and associated burdens could limit their desire for marriage. Detailed reasons for singled life among RHD need to be explored.

In this study, the mean age for RHD diagnosis was second decade of life. Moreover, children below the age of 18 years constituted a third of study population. This further reinforces the established evidence that RHD is the disease of children and young adults [30]. Ethiopia was also reported as a high endemic setting for RHD with children and young adults being most affected [10]. This underlines the need for strengthening the national RHD preventive strategies put in place to avert the national productivity loss [12].

In our study, majority of RHD subjects had moderate to severe valvular lesions on echocardiography. RHD disease progression in Sub-Saharan Africa was reported to be more accelerated [26, 31]. Lack of readily available definitive management could also make the case for such a severe disease distribution [22]. Our study subjects didn't have major associated chronic illnesses. However, this should be interpreted in light of the younger of age 
Table 2 Clinical characteristics and Chi-square analysis outputs of Rheumatic Heart Disease study subjects at Tikur Anbessa Specialized Hospital, 2021

\begin{tabular}{|c|c|c|c|c|c|}
\hline \multirow[t]{2}{*}{ Variable } & \multirow[t]{2}{*}{ Frequency(n) } & \multirow[t]{2}{*}{ Percentage- (\%) } & \multicolumn{3}{|c|}{ SWB: $\mathrm{n}(\%), P$ value } \\
\hline & & & Poor & Normal & $P$ Value \\
\hline Age at RHD diagnosis(yrs) & & & & & 0.005 \\
\hline$<20$ & 264 & 68.8 & $18(6.8)$ & 246(93.2) & \\
\hline 20 and above & 120 & 31.2 & 19(15.8) & $101(84.2)$ & \\
\hline RHD severity & & & & & 0.456 \\
\hline Mild & 54 & 14.1 & $4(7.4)$ & $50(92.6)$ & \\
\hline Moderate & 86 & 22.4 & $6(7)$ & $80(93)$ & \\
\hline Severe & 244 & 63.5 & $27(11.1)$ & 217(88.9) & \\
\hline Any comorbidity & & & & & 0.126 \\
\hline No & 324 & 84.4 & 28(8.6) & 296(91.4) & \\
\hline Yes & 60 & 15.6 & $9(15)$ & $51(85)$ & \\
\hline Common Comorbidities or conditions & & & & & 0.120 \\
\hline Seizure disorders & 7 & 1.8 & $1(14.3)$ & $6(85.7)$ & \\
\hline Hypertension & 5 & 1.3 & $1(20)$ & $4(80)$ & \\
\hline HIV & 4 & 1.0 & $0(0)$ & $4(100)$ & \\
\hline Chorea & 4 & 1.0 & $1(25)$ & $3(75)$ & \\
\hline Pregnancy & 2 & 0.5 & $0(0)$ & $2(100)$ & \\
\hline $\begin{array}{l}\text { Others (anemia, myoma, pituitary adenoma, } \\
\text { hypothyroidism etc) }\end{array}$ & 24 & 6.3 & $4(16.7)$ & 20(83.3) & \\
\hline NYHA class & & & & & 0.366 \\
\hline I & 76 & 19.8 & $5(6.6)$ & $71(93.4)$ & \\
\hline$\|$ & 164 & 42.7 & 15(9.1) & 149(90.9) & \\
\hline III & 50 & 13 & $8(16)$ & $42(84)$ & \\
\hline IV & 94 & 24.5 & $9(9.6)$ & $85(90.4)$ & \\
\hline RHD related complication & & & & & 0.360 \\
\hline $\mathrm{HF}$ & 48 & 12.5 & $4(8.3)$ & $44(91.7)$ & \\
\hline Stroke & 16 & 4.2 & $0(0)$ & $16(100)$ & \\
\hline Rheumatic Recurrence & 18 & 4.7 & $0(0)$ & $18(100)$ & \\
\hline Others (AF, AV block, LA thrombus...) & 46 & 12 & $8(17.4)$ & $38(82.6)$ & \\
\hline Number of drugs & & & & & 0.880 \\
\hline Single & 9 & 2.3 & $1(11.1)$ & $8(88.9)$ & \\
\hline Multiple & 375 & 97.7 & $36(9.6)$ & 339(90.4) & \\
\hline Adherence to medications & & & & & 0.021 \\
\hline Good & 297 & 77.3 & $23(7.7)$ & 274(92.3) & \\
\hline Poor or Satisfactory & 87 & 22.7 & 14(16.1) & 73(83.9) & \\
\hline Psychological support obtained from & & & & & 0.000 \\
\hline Family & 349 & 90.9 & $27(7.7)$ & $322(92.3)$ & \\
\hline Friends & 35 & 9.1 & 10(28.6) & 25(71.4) & \\
\hline Hospital admission in the last 1 year & & & & & 0.086 \\
\hline Yes & 100 & 26 & $14(14)$ & $86(86)$ & \\
\hline No & 284 & 74 & $23(8.1)$ & 261(91.9) & \\
\hline RHD intervention (Surgical or device) & & & & & 0.770 \\
\hline Yes & 66 & 17.2 & $7(10.6)$ & $59(89.4)$ & \\
\hline No & 318 & 82.8 & $30(9.4)$ & 288(90.6) & \\
\hline Nutritional status & & & & & 0.205 \\
\hline Normal & 337 & 87.8 & $31(9.2)$ & 306(90.8) & \\
\hline Mild wasting & 29 & 7.6 & $4(13.8)$ & $25(86.2)$ & \\
\hline Moderate wasting & 16 & 4.2 & $1(6.3)$ & 15(93.8) & \\
\hline
\end{tabular}


Table 2 (continued)

\begin{tabular}{llllll}
\hline Variable & Frequency $(\mathbf{n})$ & Percentage- (\%) & & \multicolumn{2}{l}{ SWB: $\mathbf{n}(\%), P$ value } \\
\cline { 4 - 5 } & & & Poor & Normal & $P$ Value \\
\hline Severe wasting & 2 & 0.5 & $1(50)$ & $1(50)$ & \\
\hline
\end{tabular}

Table 3 Subjective wellbeing score of rheumatic heart disease patients at Tikur Anbessa Hospital based on WHO 5 wellbeing score, 2021

\begin{tabular}{|c|c|c|c|c|c|c|}
\hline \multicolumn{7}{|l|}{$\begin{array}{l}\text { Variable } \\
\text { SWB score }\end{array}$} \\
\hline \multicolumn{7}{|l|}{ SWB score } \\
\hline 13 or above & \multicolumn{6}{|c|}{$347(90.4)$} \\
\hline Below 13 & \multicolumn{6}{|l|}{$37(9.6)$} \\
\hline \multirow[t]{2}{*}{ SWB individual Scores } & \multicolumn{6}{|c|}{ Score, n (\%) } \\
\hline & 0 & 1 & 2 & 3 & 4 & 5 \\
\hline WHO1 & $10(2.6)$ & $19(4.9)$ & 15(3.9) & $46(12)$ & $120(31.3)$ & 174(45.3) \\
\hline WHO2 & $9(2.3)$ & $19(4.9)$ & $10(2.6)$ & $57(14.8)$ & $122(31.8)$ & $167(43.5)$ \\
\hline $\mathrm{WHO} 3$ & $8(2.1)$ & $22(5.7)$ & $15(3.9)$ & $57(14.8)$ & 112(29.2) & $170(44.3)$ \\
\hline WHO4 & $9(2.3)$ & $19(4.9)$ & $9(2.3)$ & $47(12.2)$ & $105(27.3)$ & $195(50.8)$ \\
\hline WHO5 & $20(5.2)$ & $15(3.9)$ & $20(5.2)$ & $63(16.4)$ & $115(29.9)$ & $151(39.3)$ \\
\hline
\end{tabular}

Table 4 Multivariable logistic regression output of factors associated with poor SWB among patients with Rheumatic Heart Disease at Tikur Anbessa Specialized Hospital, 2021

\begin{tabular}{|c|c|c|c|c|c|c|}
\hline \multirow[t]{2}{*}{ Variable } & \multirow[t]{2}{*}{ Categories } & \multicolumn{2}{|l|}{ SWB } & \multirow[t]{2}{*}{ COR, $P$ value } & \multicolumn{2}{|l|}{ AOR $P$ value } \\
\hline & & Poor SWB & Normal & & & \\
\hline \multicolumn{7}{|c|}{ Family income } \\
\hline & $<1000$ & 15 & 65 & $2.89(1.26-6.65)$, P 0.012 & $2.97(1.24-7.1)$ & 0.014 \\
\hline & 1000-2999 & 11 & 144 & $0.96(0.40-2.2)$, P 0.923 & $0.9(0.37-2.2)$ & 0.082 \\
\hline & $\geq 3000$ & 11 & 138 & 1 & 1 & \\
\hline \multicolumn{7}{|c|}{ Age at RHD diagnosis } \\
\hline & $<20$ & 18 & 246 & 0.39(0.19-0.77), P 0.007 & $2.69(1.30-5.58)$ & 0.008 \\
\hline & $\geq 20$ & 19 & 101 & 1 & 1 & \\
\hline \multicolumn{7}{|c|}{ Adherence } \\
\hline & Good & 23 & 274 & $0.44(0.22-0.89)$, P 0.023 & $0.37(0.18-0.77)$ & 0.028 \\
\hline & Poor/Satisfactory & 14 & 73 & 1 & 1 & \\
\hline \multicolumn{7}{|c|}{ Psychologic support } \\
\hline & Family & 27 & 322 & $0.21(0.09-0.48)$, P 0.000 & $0.26(0.11-0.64)$ & 0.003 \\
\hline & Others & 10 & 25 & 1 & 1 & \\
\hline
\end{tabular}

of our study population where occurrence of chronic illnesses is said to be low.

In this study, heart failure, stroke and rheumatic recurrences were the most common documented RHD complications. Similar pattern was also reported in other studies [32-34]. Such a course is expected in the nonintervened RHD patients. Majority of RHD subjects were on multiple medications with good adherence. Good medication adherence was also reported in other studies
[35, 36]. Our study subjects were already enrolled on chronic care, the medical care and clinical recommendations might have contributed to good medication adherence. However, the self-report of adherence could have inflated adherence responses.

In the current study, one tenth of RHD cases had poor SWB. There are no similar studies done on RHD to compare our figure. We believe this is significant given the burden of RHD in the nation and developing 
countries. Hence, it calls for timely consideration and prompt action.

In our study, family income less than 1000ETB was positively associated with poor SWB. The association between income and SWB is an area of debate among experts. High income was documented to be associated with poor SWB [37]. Weak or no association was reported in a meta-analysis [38]. Other studies documented positive association between income and wellbeing [39]. Further mixed qualitative and quantitative studies are recommended to explore this subject.

Younger age at RHD diagnosis, $<20$ years, was positively associated with poor SWB. This is in agreement with the global report that documented reduced life satisfaction among adolescents [40]. Important life changes that included mood and life satisfaction, and expectation at school performance are known to affect SWB in adolescents [41]. Positive youth development through positive self-image, personal wellness, current or future aspirations and family connectedness were reported to associate with positive SWB among adolescents [42]. Presence of an established RHD with lack of access to definitive surgical interventions could put our study subjects at increased odds for poor SWB.

Good medication adherence was negatively associated with poor SWB in this study. Similar finding was reported in other chronic illness [43]. Good adherence was also reported to be associated with improved health outcomes and hence positive SWB [44]. Effects of cardiac medications on autonomic function could have contributed to good adherence and positive SWB. Reduced autonomic dysfunction that clinically translates to low heart rate variability, lower systolic blood pressure, and faster cardiovascular recovery was reported to be associated with positive SWB $[45,46]$. Medication adherence could promote and associate to other healthy behaviors like healthy eating, physical activity, smoking cessation, and improved SWB [18, 47]. Further explorative mixed studies are needed to understand how medication adherence relates to SWB among RHD patients.

Psychological support from families was negatively associated with poor SWB in this study. Similar report was documented in another study [48]. Various assistances for chronically ill patients on chronic medications might help to improve their SWB [49]. However, absence of association was reported in another study. Their proposed explanation was that social support could provide comfort but might have negative effect on SWB or selfesteem [50]. While details are yet to be studied, Ethiopians have strong family and social supports schemes and that might have contributed for the strong family support and hence positive SWB.
The strengths of our study include inclusion of large sample from the majorly non-intervened RHD and use of validated SWB assessment tool, prospective data collection, and collection of social, demographic and clinical variables. Our study has some limitations. First, we have assessed medication adherence based on self-report and that has overrating risk. Second, we employed questionnaire-based study and we couldn't exhaust assessment of predictors for SWB among the RHD as that will additionally require qualitative component for triangulation. Thirdly, we were not able to adjust for more variables due to sample of the study and small number of variables in final model. Lastly, our study analysis employed data mining approach owing to lack of evidence on determinants of SWB among RHD subjects. Future studies should consider the out puts of this study and other related literatures during analysis. However, this study provides insightful information on the quality of life among RHD patients and their associated risk for depression. It also helps policy makers to consider SWB assessment as a routine care in addition to the mandatory advancement of RHD interventions in our patients and in similar settings.

\section{Conclusion}

In our study, one tenth of RHD subjects had poor SWB. Children and young adults with second decade of life RHD diagnosis predominated. Echocardiographically, most of them had moderate to severe RHD disease. Majority were in NYHA class I and II, and lived within $100-\mathrm{km}$ from the follow up health facility. Heart failure was the most common reported RHD complication. Majority were on multiple medications with good adherence. Families provided psychologic support in most cases. Only a little over one tenth had surgical intervention for RHD. Family income, age at RHD diagnosis, medication adherence and psychological support predicted poor SWB among RHD subjects. Poor SWB has to be considered and assessed among RHD patients particularly among those with younger age at RHD diagnosis and poor family income. Further mixed studies are recommended to assess how medication adherence and psychological supports associate with positive SWB among RHD patients.

\footnotetext{
Abbreviations

AF: Atrial Fibrillation; aOR: Adjusted odds ratio; AV block: Atrioventricular block; COR: Crude odds ratio; ETB: Ethiopian Birr; HF: Heart Failure; HIV: Human Immunodeficiency Virus; IE: Infective Endocarditis; LA: Left Atrium; MD: Medical doctor; MS: Masters of science; NYHA: New York Health Association; PhD: Doctorate of Philosophy; RHD: Rheumatic Heart Disease; RTA: Road Traffic Accident; SNNPR: Southern Nations and Nationalities Peoples Regional State; SPSS: Statistical Package for Social Sciences; SWB: Subjective Wellbeing; TASH: Tikur Anbessa Specialized Hospital; WHO: World Health Organization.
} 


\section{Supplementary Information}

The online version contains supplementary material available at https://doi. org/10.1186/s12913-021-07378-0.

\section{Additional file 1.}

Additional file 2 .

\section{Acknowledgments}

We thank all study participants who contributed for this output. We would like to extend our sincere thanks to Dr. Negussie Deyessa at School of Public Health, College of Health Sciences, Addis Ababa University (AAU) for providing and giving us permission to use validated WHO-5 Amharic version SWB tool. We also thank our data collectors for their time. We thank Establishing RHD Centre of Excellence Project at Addis Ababa University-Federal Ministry of Health (AAU-FMOH), Ethiopia for sponsoring this study.

\section{Authors' contributions}

HT wrote draft proposal, prepared data collection tools, supervised data collection, analyzed the data, and wrote the manuscript. HA and HM contributed to proposal development, prepared data collection tools, supervised data collection, and commented different versions of the manuscript. EG, SG and DY contributed to proposal development, data collection tools, and commented different versions of the manuscript. All authors read and approved the final manuscript.

\section{Funding}

Funding was obtained from Establishing RHD Centre of Excellence Project, Addis Ababa University-Federal Ministry of Health (AAU-FMOH), Ethiopia. The funder didn't have any role in the data collection, analysis and write up of the manuscript.

\section{Availability of data and materials}

The datasets analyzed during this study are available from the corresponding author on reasonable request.

\section{Declarations}

\section{Ethical approval and consent to participate}

The study was conducted in accordance to Declaration of Helsinki. Ethical clearance was obtained from Institutional Review Board of College of Health Sciences, Addis Ababa University with protocol number 097/20/Pedi on meeting number 10/2020. Participation in the study was voluntary and respondents were clearly informed about the purpose of the study and the information required from them. Their full right of non-involvement and the right to stop their participation at any point in time was ensured. Informed and written consents from parents of children under 18 and from all adult participants was obtained. A verbal assent was obtained from children between the ages of 12 and 18. Confidentiality of collected data was maintained. Patients with raw well-being score below 13 were linked to psychiatric clinic for depression assessment and follow up.

\section{Consent for publication}

Not applicable.

\section{Competing interests}

The authors declare that they have no competing interests.

\section{Author details}

${ }^{1}$ Department of Pediatrics and Child Health, Cardiology Division, School of Medicine, College of Health Sciences, Addis Ababa University, Addis Ababa, Ethiopia. ${ }^{2}$ Department of Internal Medicine, Cardiology Division, School of Medicine, College of Health Sciences, Addis Ababa University, Addis Ababa, Ethiopia.

Received: 20 August 2021 Accepted: 29 November 2021

Published online: 19 December 2021

\section{References}

1. World Health Organization. Constitution of the World Health Organization. In: World Health Organization: basic documents. 45th ed. World Health Organization Geneva; 2005

2. Amina J, Mohammed TAG. Healthy living, well-being and the sustainable development goals. Bull World Health Org. 2018;96:590-590A.

3. Diener E, Oishi S, Lucas RE. Personality, culture, and subjective wellbeing: emotional and cognitive evaluations of life. Annu Rev Psychol. 2003:54:403-25.

4. Diener E. Subjective well-being. The science of happiness and a proposal for a national index. Am Psychol. 2000;55(1):34-43.

5. Diener EE. Social indicators research series : Vol. 39. Assessing well-being: The collected works of Ed Diener. Diener EE, editor: Springer Science + Business Media; 2009.

6. Psychiatry research unit. World Health Organization. WHO (five) wellbeing index (1998 version). Geneva; 1998.

7. Topp CW, Ostergaard SD, Sondergaard S, Bech P. The WHO-5 well-being index: a systematic review of the literature. Psychother Psychosom. 2015;84(3):167-76.

8. Carapetis JR. Rheumatic heart disease in developing countries. N Engl J Med. 2007;357(5):439-41.

9. Carapetis JR. Letter by Carapetis regarding article, "is primary prevention of rheumatic fever the missing link in the control of rheumatic heart disease in Africa?". Circulation. 2010;121(15):e384 author reply e5.

10. Yadeta D, Hailu A, Haileamlak A, Gedlu E, Guteta S, Tefera E, et al. Prevalence of rheumatic heart disease among school children in Ethiopia: a multisite echocardiography-based screening. Int J Cardiol. 2016;221:260-3.

11. Yadeta D, Guteta S, Alemayehu B, Mekonnen D, Gedlu E, Benti H, et al. Spectrum of cardiovascular diseases in six main referral hospitals of Ethiopia. Heart Asia. 2017:9(2):e010829.

12. Dejuma Yadeta SG, Gedlu E, Moges T, Chanie Y, Walelgne W. National training on rheumatic heart disease prevention \& control for health care workers in Ethiopia: participant's manual. Addis Ababa: Ministry of Health-Ethiopia; 2017

13. Watkins D, Zuhlke L, Engel M, Daniels R, Francis V, Shaboodien G, et al Seven key actions to eradicate rheumatic heart disease in Africa: the Addis Ababa communique. Cardiovasc J Afr. 2016;27(3):184-7.

14. African Union. "Challenges for inclusive and universal access", Development of a Roadmap for the Eradiation of Rheumatic Heart Disease in Africa. In: first meeting of the specialised technical committee on health pdf, editor. 2015.

15. Sabreena Sheikh SD, Ansari AH, Kumar MM. The association of quality of life between anxiety and depression in patients with chronic rheumatic heart disease. Mediterranean. J Clin Psychol. 2019;7(2).

16. Ormel J, Von Korff M, Burger H, Scott K, Demyttenaere K, Huang Y-q, et al. Mental disorders among persons with heart disease - results from world mental health surveys. Gen Hosp Psychiatry. 2007;29(4):325-34.

17. Pressman SD, Cohen S. Does positive affect influence health? Psychol Bull. 2005;131(6):925-71

18. Boehm JK, Kubzansky LD. The heart's content: the association between positive psychological well-being and cardiovascular health. Psychol Bull. 2012:138(4):655-91.

19. $\operatorname{Sin~NL.~The~protective~role~of~positive~well-being~in~cardiovascular~dis-~}$ ease: review of current evidence, mechanisms, and clinical implications. Curr Cardiol Rep. 2016;18(11):106

20. Manzoni GM, Cribbie RA, Villa V, Arpin-Cribbie CA, Gondoni L, Castelnuovo G. Psychological well-being in obese inpatients with ischemic heart disease at entry and at discharge from a four-week cardiac rehabilitation program. Front Psychol. 2010;1:38.

21. Wu S-FV. Rapid screening of psychological well-being of patients with chronic illness: reliability and validity test on WHO-5 and PHQ-9 scales. Depress Res Treat. 2014;2014:239490.

22. Tefera E, Nega B, Yadeta D, Chanie Y. Humanitarian cardiology and cardiac surgery in Sub-Saharan Africa: can we reshape the model? World J Pediatr Congenit Heart Surg. 2016:7(6):727-31.

23. Garland AF, Deyessa N, Desta M, Alem A, Zerihun T, Hall KG, et al. Use of the WHO's perceived well-being index (WHO-5) as an efficient and potentially valid screen for depression in a low income country. Fam Syst Health. 2018;36(2):148-58. 
24. Mass. The Criteria Committee of the New York Heart Association. Nomenclature and criteria for diagnosis of diseases of the heart and great vessels. 9th ed. Boston: Mass: Little, Brown \& Co; 1994. p. 253-6.

25. Reményi B, Wilson N, Steer A, Ferreira B, Kado J, Kumar K, et al. World Heart Federation criteria for echocardiographic diagnosis of rheumatic heart disease--an evidence-based guideline. Nat Rev Cardiol. 2012;9(5):297-309.

26. Tadele H, Mekonnen W, Tefera E. Rheumatic mitral stenosis in children: more accelerated course in sub-Saharan patients. BMC Cardiovasc Disord. 2013;13:95.

27. Negi PC, Kandoria A, Asotra S, Ganju NK, Merwaha R, Sharma R, et al. Gender differences in the epidemiology of rheumatic fever/rheumatic heart disease (RF/RHD) patient population of hill state of northern India; 9 years prospective hospital based, HP-RHD registry. Indian Heart J. 2020;72(6):552-6.

28. Carapetis JR, Beaton A, Cunningham MW, Guilherme L, Karthikeyan G, Mayosi BM, et al. Acute rheumatic fever and rheumatic heart disease. Nat Rev Dis Prim. 2016;2:15084.

29. Chang AY, Nabbaale J, Nalubwama H, Okello E, Ssinabulya I, Longenecker CT, et al. Motivations of women in Uganda living with rheumatic heart disease: a mixed methods study of experiences in stigma, childbearing, anticoagulation, and contraception. PLoS One. 2018;13(3):e0194030.

30. Kumar RK, Antunes MJ, Beaton A, Mirabel M, Nkomo VT, Okello E, et al. Contemporary diagnosis and Management of Rheumatic Heart Disease: implications for closing the gap: a scientific statement from the American Heart Association. Circulation. 2020;142(20):e337-e57.

31. Oli K, Asmera J. Rheumatic heart disease in Ethiopia: could it be more malignant? Ethiop Med J. 2004;42(1):1-8.

32. He VY, Condon JR, Ralph AP, Zhao Y, Roberts K, de Dassel JL, et al. Long-term outcomes from acute rheumatic fever and rheumatic heart disease: a data-linkage and survival analysis approach. Circulation. 2016;134(3):222-32.

33. Okello E, Wanzhu Z, Musoke C, Twalib A, Kakande B, Lwabi P, et al. Cardiovascular complications in newly diagnosed rheumatic heart disease patients at Mulago Hospital, Uganda. Cardiovasc J Afr. 2013;24(3):80-5.

34. Nigussie $B$, Tadele $H$. Heart failure in Ethiopian children: mirroring the unmet cardiac services. Ethiop J Health Sci. 2019;29(1):811-8.

35. Musoke C, Mondo CK, Okello E, Zhang W, Kakande B, Nyakoojo W, et al. Benzathine penicillin adherence for secondary prophylaxis among patients affected with rheumatic heart disease attending Mulago hospital. Cardiovasc J Afr. 2013;24(4):124-9.

36. Adem A, Dukessa Gemechu T, Jarso H. Rheumatic heart disease patients' adherence to secondary prophylaxis and associated factors at hospitals in Jimma zone, Southwest Ethiopia: a multicenter study. Patient Prefer Adherence. 2020;14:2399-406.

37. Yu K, Zhang Y. Absolute income, income inequality and the subjective well-being of migrant Workers in China: toward an understanding of the relationship and its psychological mechanisms. Int J Environ Res Public Health. 2019;16(14)

38. Ngamaba KH, Panagioti M, Armitage CJ. Income inequality and subjective well-being: a systematic review and meta-analysis. Qual Life Res. 2018;27(3):577-96.

39. Gildner TE, Liebert MA, Capistrant BD, D'Este C, Snodgrass JJ, Kowal P. Perceived income adequacy and well-being among older adults in six low- and middle-income countries. J Gerontol B Psychol Sci Soc Sci. 2019;74(3):516-25.

40. Marquez J, Long E. A global decline in adolescents' subjective wellbeing: a comparative study exploring patterns of change in the life satisfaction of 15 -year-old students in 46 countries. Child Indic Res. 2021;14(3):1251-92

41. Steinmayr R, Wirthwein L, Modler L, Barry MM. Development of subjective well-being in adolescence. Int J Environ Res Public Health. 2019;16(19):3690.

42. Henson M, Sabo S, Trujillo A, Teufel-Shone N. Identifying protective factors to promote health in American Indian and Alaska native adolescents: a literature review. J Prem Prev. 2017;38(1-2):5-26.

43. Reis AC, Guerra MN, Lencastre LM. Treatment adherence and subjective well-being in HIV/AIDS infection. AIDS Care. 2013;25(12):1604-11.

44. Kubzansky LD, Huffman JC, Boehm JK, Hernandez R, Kim ES, Koga HK, et al. Positive psychological well-being and cardiovascular disease: JACC health promotion series. J Am Coll Cardiol. 2018;72(12):1382-96.
45. Oveis C, Cohen AB, Gruber J, Shiota MN, Haidt J, Keltner D. Resting respiratory sinus arrhythmia is associated with tonic positive emotionality. Emotion. 2009;9(2):265-70

46. Bacon SL, Watkins LL, Babyak M, Sherwood A, Hayano J, Hinderliter AL, et al. Effects of daily stress on autonomic cardiac control in patients with coronary artery disease. Am J Cardiol. 2004;93(10):1292-4.

47. DuBois CM, Beach SR, Kashdan TB, Nyer MB, Park ER, Celano CM, et al. Positive psychological attributes and cardiac outcomes: associations, mechanisms, and interventions. Psychosomatics. 2012;53(4):303-18.

48. Siedlecki KL, Oishi S, Jeswani S. The relationship between social support and subjective well-being across age. Soc Indic Res. 2014;117(2):561-76.

49. Thomas PA. Is it better to give or to receive? Social support and the wellbeing of older adults. J Gerontol B Psychol Sci Soc Sci. 2010;65b(3):351-7.

50. Lepore SJ, Glaser DB, Roberts KJ. On the positive relation between received social support and negative affect: a test of the triage and selfesteem threat models in women with breast cancer. Psychooncology. 2008;17(12):1210-5.

\section{Publisher's Note}

Springer Nature remains neutral with regard to jurisdictional claims in published maps and institutional affiliations.
Ready to submit your research? Choose BMC and benefit from:

- fast, convenient online submission

- thorough peer review by experienced researchers in your field

- rapid publication on acceptance

- support for research data, including large and complex data types

- gold Open Access which fosters wider collaboration and increased citations

- maximum visibility for your research: over $100 \mathrm{M}$ website views per year

At BMC, research is always in progress.

Learn more biomedcentral.com/submissions 